\title{
錠剤のスティッキングに及ぼす打錠圧力及び臼壁面圧力の影響
}

\author{
垣 見 和之, ${ }^{*}$ 丹羽敏 幸, 檀上和 美
}

\section{Influence of Compression Pressure and Die-wall Pressure on Tablet Sticking}

\author{
Kazuyuki KAKIMI, ${ }^{*}$ Toshiyuki NIWA, and Kazumi DANJO \\ Faculty of Pharmacy, Meijo University, 150 Yagotoyama, Tempaku-ku, Nagoya 468-8503, Japan
}

(Received November 10, 2010; Accepted December 14, 2010; Published online December 27, 2010)

\begin{abstract}
An eccentric-type tablet machine fitted with 8-mm-diameter flat-faced punches was used to measure the forces of upper and lower punches, die-wall pressure, tablet ejection force, and scraper pressure (SCR), a type of shear stress, to evaluate sticking behavior. The shear stress between the surfaces of the tablet and lower punch was determined using an SCR detection system. Mean surface roughness $\left(R_{\mathrm{a}}\right)$ of tablets, measured by laser scanning microscopy, was used to estimate the magnitude of sticking. Tablet tensile strength tended to increase with compression pressure, which is consistent with previous reports. SCR decreased with increasing compression pressure for samples at all formulations (i.e., for different kinds and percentages of lubricant). $R_{\mathrm{a}}$ associated with sticking increased with SCR, indicating that the adhesive force between the particles of the tablet surface and the lower punch surface plays an important role in sticking. Multiple linear regression analysis with SCR as the response variable was conducted. Upper and lower punch force, diewall pressure, tablet ejection force, SCR, percentage of lubricant, and tensile strength of tablet were selected as explanatory variables. Results of this analysis indicate that the incidence of sticking decreased when either the lower punch force or die-wall pressure increased, where, of these two, increasing the lower punch force had a stronger effect on decreasing SCR.
\end{abstract}

Key words_— scraper pressure; surface roughness; compression pressure; die-wall pressure; multiple linear regression analysis

$$
\text { 緒言 }
$$

錠剤表面粒子と杵表面との付着力に起因するステ イッキング及びピッキングは錠剤の製造中に生じ, 高品質な錠剂製造の障害となる，スティッキング及 びピッキングが発生する原因は以下のように分類で きる.

1）錠剤処方中物質の融点, 粒子径, 粒度分布, 表面状態及び打錠用顆粒の強度といつた物理化 学的な要因

2）杵の表面状態，打錠圧力及び打錠速度といつ た機械的な要因

3）機械周囲の温度及び湿度といった環境的な要 因 ${ }^{11}$

Schmidt $ら^{2)}$ は，杵表面から錠剤を取り除くのに 必要な力を測定しており, Naito ら ${ }^{3-5)}$ は錠剤表面の すべり力と圧縮中に下杵が受ける圧力の測定方法に

名城大学薬学部

*e-mail: k_kakimi@skk-net.com
ついて報告している．また Toyoshima ら6) は錠剂の 表面粗度（ $\mathrm{R}_{\mathrm{a}}$ ) がスティッキング予測に有効な因 子であると提案しており, Sugimori ら7)はキャッピ ングが高い残留臼壁圧により錠剤に亀裂が生じた際 に発生することを報告している。さらに近年, Sawaguchi ら ${ }^{8)}$ が EIP 技術を利用した杵を使用する ことによりスティッキング発生が減少することを報 告している，しかしながら，スティッキング及びピ ッキングに関して，打錠中リアルタイムに評価する 方法はいまだ開発されていない.

錠剤が下杵表面から脱離する際のずり応力の評価 に用いられるスクレパー圧力（SCR）の測定はステ イッキング及びピッキング評価の最も直接的な評価 方法であり, 本研究の目的は SCR の数值に基づい てスティッキング及びピッキングを定量化すること である。われわれは以前に打錠圧力と打錠速度がス ティッキング発生に及ぼす影響についてロータリー 式打錠機を用いて検討したが, 9) 今回は単発式打錠 機を用いて打錠圧力がスティッキングの発生頻度に 
与える影響をより詳細に検討した。測定は種々の打 錠圧力下で行い，打錠圧力及び臼壁圧が SCR 及び $\mathrm{R}_{\mathrm{a}}$ に及ぼす影響を明らかにした。

\section{実 験 の 部}

1. 試料試料には $p$-ヒドロキシ安息香酸ブチ ル (関東科学社製), 乳糖 (JP15 グレード, 200M, D.M.V 社製)，軽質無水ケイ酸（アエロジル 200, 日本アエロジル社製），ヒドロキシプロピルセル ロース（HPC-SL，日本曹達社製），ステアリン酸 マグネシウム（和光純薬製），フマル酸ステアリル ナトリウム（PRUV，木村産業製）を用いた.

2. 打錠用顆粒の調製 $p$-ヒドロキシ安息香酸 ブチルは自働乳鉢（ANM200W 型，日陶科学社製） にて粉砕し，ふるい分け機（スピンエアシーブ，セ イシン企業製）にて分級して $300 \mu \mathrm{m}$ 以下の粒子径 のものを使用した。粉砕した $p$-ヒドロキシ安息香 酸ブチル及び乳糖を結合液として HPC-SL の 7\% 水溶液を用い，転動流動層造粒機(アグロマスター,

AGM-2，ホソカワミクロン製）を使用して造粒し， 排気温度 $40^{\circ} \mathrm{C}$ にて乾燥を終了した。乾燥終了後造 粒物を目開き $250 \mu \mathrm{m}$ 及び $106 \mu \mathrm{m}$ のふるいを用い て分級し，粒子径が 106-250 $\mu \mathrm{m}$ の造粒物を使用し た。この造粒物とアエロジル 200 をビニール袋中で 3 分間混合した後，滑沢剂としてステアリン酸マグ ネシウムあるいはフマル酸ステアリルナトリウムを 加え, ビニール袋中で 1 分間混合した。最終的な打 錠用顆粒の処方を Table 1 に示した。

3. 打錠打錠には直径 $8 \mathrm{~mm}$ の平面杵をセッ トした単発式打錠機（Tab flex，岡田精工製）を用
いた。錠剤重量は $200 \mathrm{mg}$ とし，5, 7.5 及び $10 \mathrm{kN}$ の打錠圧力にて製錠した．打錠時には上杵荷重，下 杵荷重, 臼壁面圧力, 錠剂排出時の排出圧力及び錠 剂と下杵表面とのずり応力を SCR として経時的に 記録した。これらのパラメータの記録及び解析は打 錠圧力解析プログラム（ダアツ III，岡田精工製）を 使用した。

4. 錠剂表面粗さの測定 製錠した錠剤表面を 走査型レーザー顕微鏡（1LM21，レーザーテック 社製）にて 20 倍の対物レンズにより観察し，画像 処理システム（三谷商事株式会社製）を用いて画像 処理を行い，錠剤表面粗さ（ $\mathrm{R}_{\mathrm{a}}$ ) を測定した． $\mathrm{R}_{\mathrm{a}}$ は Eq. (1)により算出した.

$$
\mathbf{R}_{\mathrm{a}}=(1 / \mathrm{N}) \sum_{\mathrm{i}=1}^{\mathrm{N}}\left|\mathrm{z}_{\mathrm{i}}-\mathrm{z}\right|
$$

ここで $\mathrm{N}$ は全画素数であり， $\mathrm{z}_{\mathrm{i}}(\mu \mathrm{m})$ は $\mathrm{i}$ におけ る高さ, $\mathrm{z}(\mu \mathrm{m})$ は測定範囲内のすべての画素の平 均高さである.

5. 錠剤強度の測定 単発式打錠機にて製錠し た各錠剤 5 個につき，錠剤硬度計（ポータブルチェ ッカー, PC-30, 岡田精工製）を用いて直径方向に 加重を行い，錠剤の引張破断強度（ $\left.\mathrm{S}_{\mathrm{t}}\right)$ を Eq. (2) により求めた.

$$
\mathrm{S}_{\mathrm{t}}=2 \mathrm{H} /(\pi \mathrm{DL})
$$

ここで, $\mathrm{H}$ は破壊時の加重, $\mathrm{D}$ は錠剤の直径, $\mathrm{L}$ は錠剂の厚みである。

6. 重回帰分析打錠と同時に収集した上杵荷 重ピーク値, 下杵荷重ピーク值, 臼壁面圧力力積 值, 排出圧力ピーク值と, 滑沢剤濃度及び $\mathrm{S}_{\mathrm{t}}$ を要 因として用い，これらの要因が SCR に及ぼす寄与

Table 1. Formulation of Test Samples (\%)

\begin{tabular}{lccccccc}
\hline \multirow{2}{*}{ Material } & \multicolumn{7}{c}{ Formulation No. } \\
\cline { 2 - 8 } & $\mathrm{A}$ & $\mathrm{B}$ & $\mathrm{C}$ & $\mathrm{D}$ & $\mathrm{E}$ & $\mathrm{F}$ & $\mathrm{G}$ \\
\hline$n$-Butyl $p$-Hydroxybenzoate & 10.00 & $\leftarrow$ & $\leftarrow$ & $\leftarrow$ & $\leftarrow$ & $\leftarrow$ & $\leftarrow$ \\
\hline Lactose 200 & 84.85 & $\leftarrow$ & $\leftarrow$ & $\leftarrow$ & $\leftarrow$ & $\leftarrow$ & $\leftarrow$ \\
\hline HPC-SL & 3.50 & $\leftarrow$ & $\leftarrow$ & $\leftarrow$ & $\leftarrow$ & $\leftarrow$ & $\leftarrow$ \\
\hline Aerosil 200 & 1.65 & $\leftarrow$ & $\leftarrow$ & $\leftarrow$ & $\leftarrow$ & $\leftarrow$ & $\leftarrow$ \\
\hline Subtotal & 100.00 & $\leftarrow$ & $\leftarrow$ & $\leftarrow$ & $\leftarrow$ & $\leftarrow$ & $\leftarrow$ \\
\hline Magnesium stearate & 0.50 & 0.60 & 0.70 & - & - & - & - \\
\hline PRUV & - & - & - & 0.60 & 0.70 & 1.00 & 1.50 \\
\hline Summation & 100.50 & 100.60 & 100.70 & 100.60 & 100.70 & 101.00 & 101.50 \\
\hline
\end{tabular}


度を同程度に評価するため，まず Eq. (3)により最 小值 -1 , 最大值 1 と規格化した. ${ }^{10)}$ 各要因の測定 值を Table 2 に示した.

$$
\mathrm{T}_{\mathrm{ran}}=\{2 \mathrm{~A}-(\operatorname{Max}+\operatorname{Min})\} /(\operatorname{Max}-\mathrm{Min})
$$

ここで， $\mathrm{T}_{\mathrm{ran}}$ は規格值， $\mathrm{A}$ は測定值，Max 及び Min はそれぞれ測定值中の最大值及び最小值であ る.この規格值を用いて各要因の回帰定数を Excel 2007 (Ver. 12.0.654.5000, Microsoft 製)にて求め, 寄与度の高い要因についてその関係を 3 次元グラフ に示した。

\section{結 果と考 察}

\section{1. 錠剂強度に及ぼす打錠圧力の影響 一般的} に硬度や摩損度といつた錠剂の機械的強度は，錠剤 の内部構造や構成する紛体の物理的性質, 及び処方 割合によって影響される. ${ }^{11)}$ Figure 1 には打錠圧力 （上杵荷重）を変化させた場合の $\mathrm{S}_{\mathrm{t}}$ を示した．今回 の実験では，従来の報告と同様打錠圧力の増加に伴 い錠剤はより密充填構造となるため $\mathrm{S}_{\mathrm{t}}$ も大きくな つた. ${ }^{12)}$

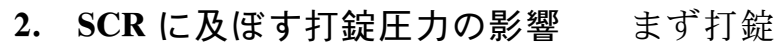
圧力を変えることによりどの程度 SCR が変化して いるかを調べた。

Figure 2 には Table 1 に示した各滑沢剂濃度の打 錠用顆粒を打錠した際の，打錠圧力（上杵荷重）に

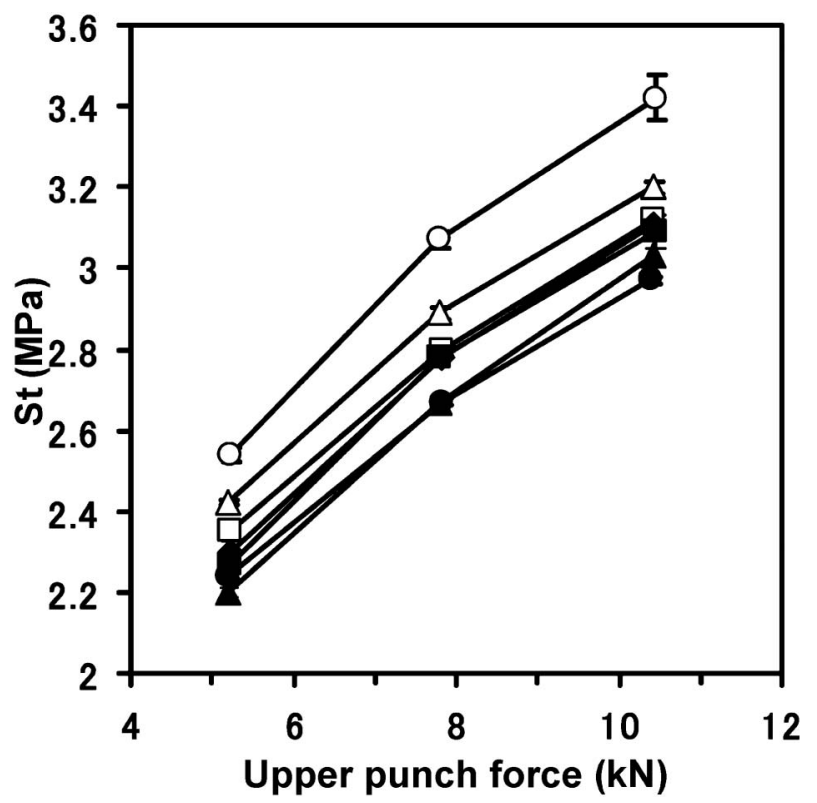

Fig. 1. Relationship between Upper Punch Force and $S_{t}$ $\bigcirc$, formulation A; $\triangle$, formulation B; $\square$, formulation $\mathrm{C}$; $\boldsymbol{O}$, formula tion $\mathrm{D} ; \boldsymbol{\Delta}$, formulation $\mathrm{E} ; \mathbf{\square}$, formulation $\mathrm{F} ; \boldsymbol{\diamond}$, formulation $\mathrm{G}$.

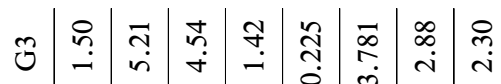

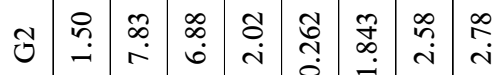

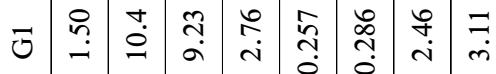

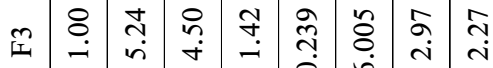

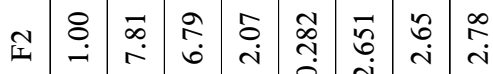

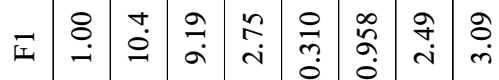

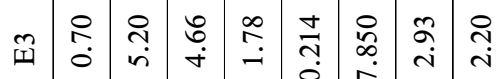

I

牙

i

ڤี

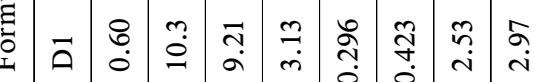

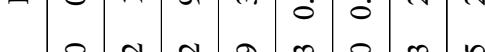

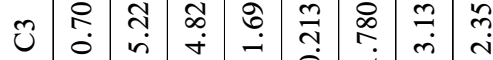

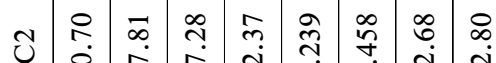

U $\stackrel{0}{\stackrel{0}{0}}$ 苟

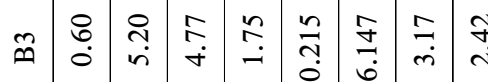

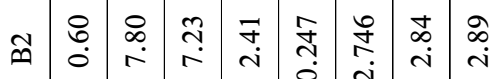

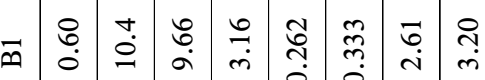

य

¿

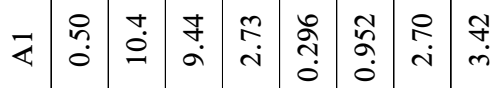

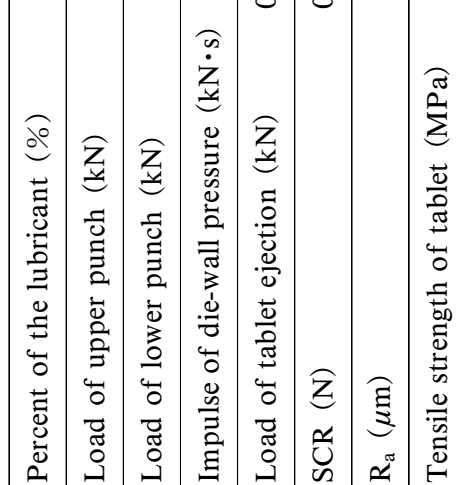




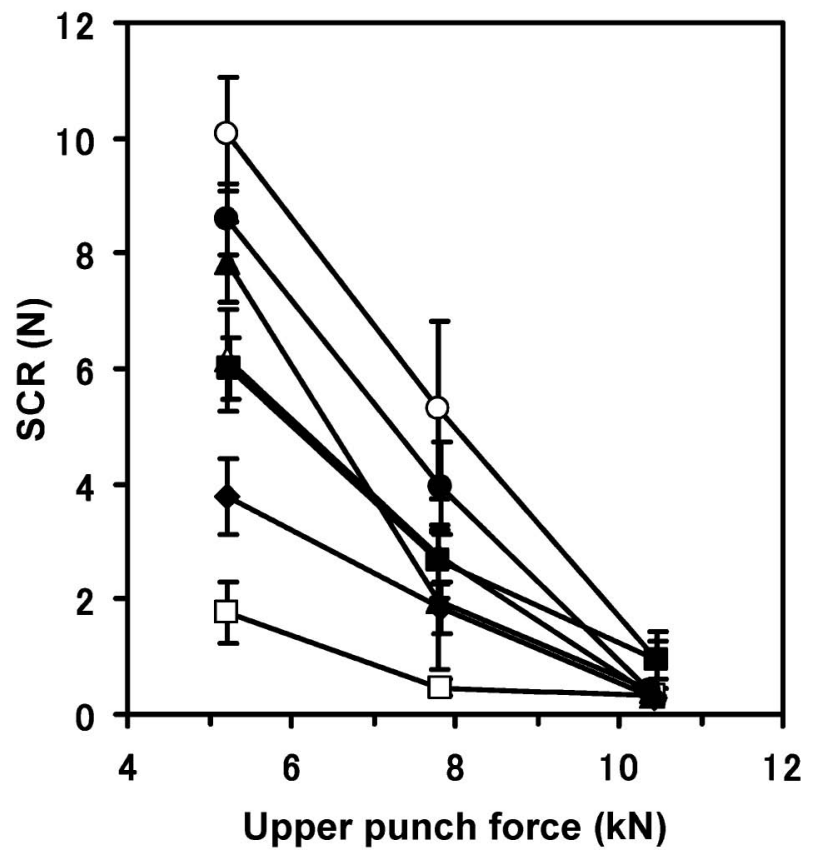

Fig. 2. Relationship between Upper Punch Force and SCR $\bigcirc$, formulation A; $\triangle$, formulation $\mathrm{B} ; \square$, formulation $\mathrm{C}$; $\boldsymbol{O}$, formulation D; $\boldsymbol{\Lambda}$, formulation E; $\boldsymbol{\square}$, formulation F; $\diamond$, formulation G.

よる SCR の変化を示した。 すべての処方において 上杵荷重の増加に伴って SCR は減少している。 上 杵圧力が増加した場合，錠剂表面粒子が下杵表面に 付着する力の上昇割合よりも，粒子間付着力の上昇 割合が大きいことから，SCR 值は減少したものと 考えられる。

3. SCR と錠剤表面粗さの関係スティッキ ングが起こった場合， $\mathrm{R}_{\mathrm{a}}$ が高くなることが報告1)さ れているため, 本検討においても走査型レーザー顕 微鏡を用いて錠剤表面状態の測定を行った． $\mathrm{R}_{\mathrm{a}}$ は 画像処理システムと Eq. (1)を用いて計算した. SCR と $\mathrm{R}_{\mathrm{a}}$ の関係は Fig. 3 に示した。 SCR と $\mathrm{R}_{\mathrm{a}}$ は 直線関係を示し $\left(\mathrm{R}^{2}=0.709\right), \mathrm{R}_{\mathrm{a}}$ はスティッキン グ傾向のよい指標であり， $\mathrm{R}_{\mathrm{a}}$ の值が大きい場合に スティッキング発生率が高いと考えられる.

\section{4. 重回帰分析重回帰分析を行った結果,}

Eq. (4)が得られた.

$$
\begin{aligned}
& \mathrm{SCR}=2.838-2.115 \mathrm{X}_{1}-1.408 \mathrm{X}_{2}+4.813 \mathrm{X}_{3} \\
& -1.862 \mathrm{X}_{4}-4.685 \mathrm{X}_{5}-2.045 \mathrm{X}_{6} \\
& n=21, \mathrm{R}=0.9329 \text {, S.E. }=1.304, \mathrm{~F}(6,14)=15.64 \\
& \text { ここで, } \mathrm{X}_{1} \text { は滑沢剂濃度の規格值， } \mathrm{X}_{2} \text { は上杵荷 }
\end{aligned}
$$
重ピーク值の規格值, $\mathrm{X}_{3}$ は下杵荷重の規格值, $\mathrm{X}_{4}$ は排出荷重の規格值, $\mathrm{X}_{5}$ は臼壁面圧力力積值の規 格值, $\mathrm{X}_{6}$ は錠剤強度の規格值, $n$ はデー夕数, $\mathrm{R}$

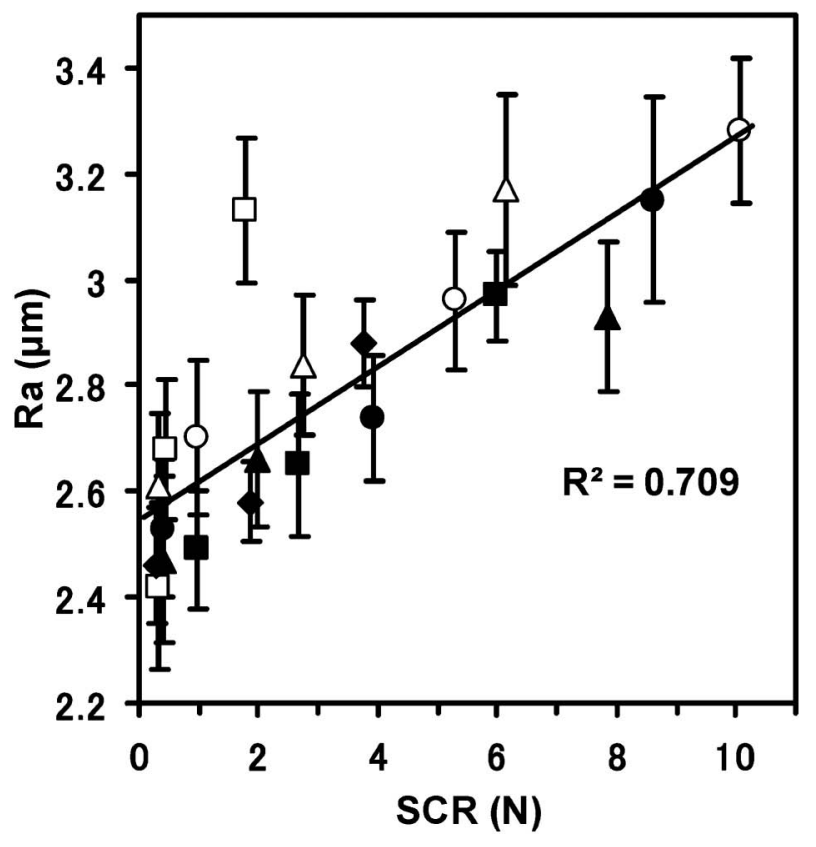

Fig. 3. Relationship between $S C R$ and $R_{a}$ $\mathrm{O}$, formulation $\mathrm{A} ; \triangle$, formulation $\mathrm{B} ; \square$, formulation $\mathrm{C} ; \boldsymbol{O}$, formulation D; $\boldsymbol{\Delta}$, formulation E; $\mathbf{\square}$, formulation F; $\diamond$, formulation G.

Table 3. Confidence Interval of Regression Coefficient of Equation (4)

\begin{tabular}{lll}
\hline \hline & \multicolumn{3}{c}{$95 \%$ Confidence interval } \\
\hline & $\mathrm{X}_{1}$ & -3.236 to -0.994 \\
\cline { 2 - 3 } Regression coefficient of & $\mathrm{X}_{2}$ & -18.113 to 15.296 \\
\cline { 2 - 3 } $\mathrm{X}_{3}$ & -21.468 to 31.095 \\
\cline { 2 - 3 } $\mathrm{X}_{4}$ & -4.774 to 1.049 \\
\cline { 2 - 3 } $\mathrm{X}_{5}$ & -12.674 to 3.304 \\
\hline $\mathrm{X}_{6}$ & -9.250 to 5.159 \\
\hline
\end{tabular}

は重相関係数，S.E. は標準誤差，F は F 検定によ る F 值を示す。また各回帰係数の信頼区間を Table 3 に示す。 SCR に対して, 下杵荷重の規格值 $\left(\mathrm{X}_{3}\right)$ ， 臼壁面圧力力積值の規格值 $\left(\mathrm{X}_{5}\right)$ の寄与度 が高かつた。

そこで, 下杵荷重の規格值及び臼壁面圧力力積值 の規格值を用いて再度重回帰分析を行い，Eq. (5) を得た。

$$
\begin{gathered}
\mathrm{SCR}=2.677-2.636 \mathrm{X}-0.721 \mathrm{Y}-0.95 \mathrm{XY} \quad(5) \\
n=21, \mathrm{R}=0.8168, \mathrm{~S} . \mathrm{E} .=1.896, \mathrm{~F}(3,17)=11.36 \\
\text { ここで, } \mathrm{X} \text { は下杵荷重の規格值, } \mathrm{Y} \text { は臼壁面圧力 } \\
\text { 力積值の規格值, } n \text { はデー夕数, } \mathrm{R} \text { は重相関係数, } \\
\text { S.E. は標準誤差, } \mathrm{F} \text { は } \mathrm{F} \text { 検定による } \mathrm{F} \text { 值を示す. }
\end{gathered}
$$


Table 4. Confidence Interval of Regression Coefficient of Equation (5)

\begin{tabular}{lcc}
\hline \hline & & $95 \%$ Confidence interval \\
\hline & $\mathrm{X}$ & -6.423 to -1.149 \\
\cline { 2 - 3 } Regression coefficient of & $\mathrm{Y}$ & -5.204 to 3.762 \\
\cline { 2 - 3 } & $\mathrm{XY}$ & -1.493 to 3.393 \\
\hline
\end{tabular}
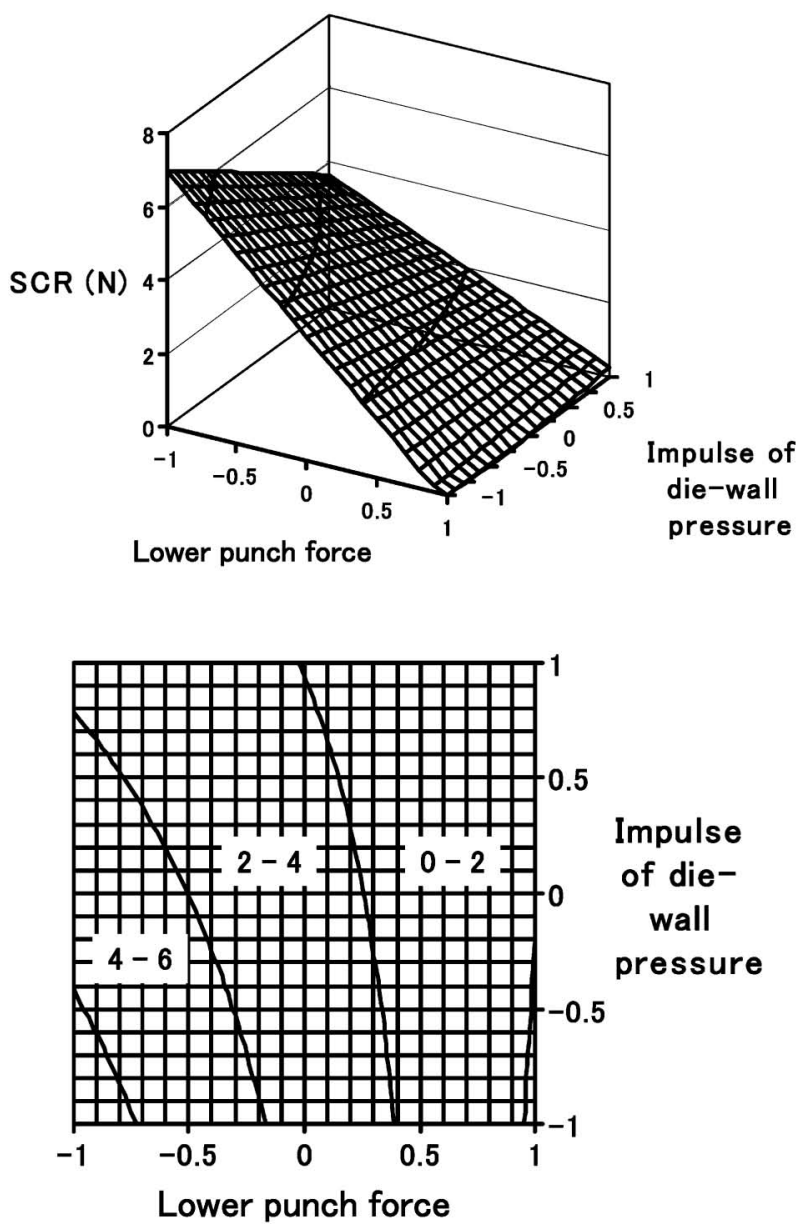

Fig. 4. SCR as Function of Impulse of Die-wall Pressure and Lower Punch Force

また各回帰係数の信頼区間を Table 4 に示す.

Equation（5)から，SCR は下杵荷重（X）と臼壁 面圧力力関值（Y）により大きく影響を受けること が推察される.そこで，Eq. (5)の関係は Fig. 4 に 示した．本検討で使用した単発式打錠機は打錠の 際，下杵位置を固定して上杵により圧縮を行う機構 であるが，打錠圧力を増加させたとき，すなわち上 杵荷重を増加させた場合に，下杵荷重あるいは臼壁 圧力が増加すると SCR が低くなる結果が得られ た。また粉体層の圧力伝達が悪い場合，すなわち上
杵荷重を増加させたときに，臼壁圧力が変わらず， ほぼ下杵荷重のみが増加した場合のほうが，粉体層 の圧力伝達がよく，下杵荷重及び臼壁圧力両者が増 加した場合よりも SCR が低くなり，スティッキン グ防止には錠剂表面粒子と錠剂内部粒子の付着力が 重要であることを示唆した。

$$
\text { ま と め }
$$

今回用いた処方では，打錠圧力を増加させた場合 SCR は減少し，スティッキングが発生し難くなっ た。重回帰分析の結果，打錠圧力を増加させた場合 に下杵荷重あるいは壁圧力が増加すると SCR が 低くなる結果が得られ，上杵荷重を増加させたとき に，臼壁圧力が変わらず，ほぼ下杵荷重のみが増加 した場合のほうが，粉体層の圧力伝達がよく，下杵 荷重及び臼壁圧力両者が増加した場合よりも SCR が低くなり，スティッキング防止には錠剤表面粒子 と錠剤内部粒子の付着力が重要であることを示唆し た.

\section{REFERENCES}

1) Danjo K., Kojima S., Chen Y.-C., Sunada H., Otsuka A., Chem. Pharm. Bull., 45, 706-709 (1997).

2) Schmidt Von P. C., Stefens K. J., Kneble G., Pharm. Ind., 45, 800-805 (1983).

3) Naito S., Nakamichi K., Chem. Pharm. Bull., 17, 2507-2514 (1969).

4) Naito S., Shimizu I., Iwaki S., Chem. Pharm. Bull., 19, 1949-1956 (1971).

5) Naito S., Masui K., Shiraki T., J. Pharm. Sci., 66, 254-259 (1977).

6) Toyoshima K., Yasumura M., Onishi N., Ueda Y., Int. J. Pharm., 46, 211-215 (1988).

7) Sugimori K., Mori S., Powder Technol., 58, 259-264 (1989).

8) Sawaguchi K., Uemura T., Mizushima Y., Pharm Tech Japan, 24, 1577-1580 (2009) .

9) Kakimi K., Niwa T., Danjo K., Chem. Pharm. Bull., 58, 1565-1568 (2010).

10) Bi Y. X., Sunada H., Yonezawa Y., Danjo K., Drug Dev. Ind. Pharm., 25, 571-581 (1999).

11) Aoki S., Danjo K., Yakugaku Zasshi, 118, 511 -518 (1998).

12) Goto K., Sunada H., Danjo K., Yonezawa Y., Drug Dev. Ind. Pharm., 25, 869-878 (1999). 